Published as: Lovreglio R., Fonzone A., dell'Olio L., Borri D., 2016, A Study of Herding Behaviour in Exit Choice during Emergencies based on Random Utility Theory, Safety Science, Vol. 82, pp. 421-431, DOI: http://dx.doi.org/10.1016/j.ssci.2015.10.015

\title{
A Study on Herding Behaviour in Exit Choice during Emergencies based on Random Utility Theory
}

\begin{abstract}
Modelling human behaviour in emergencies has become an important issue in safety engineering. Good behavioural models can help increase the safety of transportation systems and buildings in extreme situations like fires or terrorist attacks. Although it is well known that the interaction with other decision makers affects human behaviour, the role of social influences during evacuations still needs to be investigated. This paper contributes to fill this gap by analysing the occurrence of Herding Behaviour (HB) in exit choice. Theoretical explanations of $\mathrm{HB}$ are presented together with some modelling approaches used in different fields where $\mathrm{HB}$ is relevant. A discrete choice stated preference experiment is then carried out to study the role of $\mathrm{HB}$ in the decision-making process concerning exit choice during evacuation. A binary logit model is proposed showing that the occurrences of $\mathrm{HB}$ are affected by both environmental and personal factors. In particular, the model shows that the personal aptitude to HB can have a key role in selecting an exit.
\end{abstract}

Keywords: Evacuation modelling, herding behaviour, exits choice, social influences, random utility theory

\author{
Abbreviations \\ HB: Herding Behaviour \\ HC: High herding Class \\ ISI: Informational Social Influence \\ LC: Low herding Class \\ MC: Medium herding Class \\ NSI: Normative Social Influence \\ RUT: Random Utility Theory \\ SIT: Social Influence Theory \\ SPT: Social Proof Theory
}

\section{Introduction}

Many studies on evacuation issues, in the last few decades, have proved that the existing transportation systems and buildings do not always provide adequate levels of safety (Fridolf et al. 2013; Averill et al. 2005). An estimate of the safety condition of transportation systems and buildings can be performed with the application of a performance based design approach, e.g. by comparing the available safe egress time and required safe egress time (Purser 2003). Several macroscopic and microscopic models and software packages have been developed to estimate the required safe egress time (Kuligowski et al. 2010; Gwynne et al. 1999). However, the validity of these models may be limited due to the existing lack of knowledge regarding human behaviour during emergencies, as reported in the literature (Lovreglio, Ronchi, et al. 2014). 
The act of evacuating from a building and transportation systems requires the occupants to develop and take different decisions (e.g. to investigate and to seek more information on the situation, to evacuate, to choose an exit, etc.) (Lovreglio 2014; Lovreglio et al. 2015; Lovreglio, Ronchi, et al. 2015b). Among these, once the decision to evacuate has been taken, exit choice is surely one of the most important (Ronchi, Colonna, et al. 2012; Ronchi, Nilsson, et al. 2012). Exit choice can be influenced by both physical factors (e.g. evacuees' mobility, presence of obstacles, visibility, etc.) (Jeon et al. 2011; Kobes et al. 2010) and social factors (e.g. behaviour of other evacuees, etc.) (Lovreglio, Borri, et al. 2014; Kinateder 2012).

Different models and theories have been developed to explain social interactions during evacuations. The four commonly accepted theories are the Role-rule Theory (Canter et al. 1980), the Affiliative Theory (Sime 1985), the Social Influence Theory (SIT) (Nilsson \& Johansson 2009) and Caldini's Social Proof Theory (SPT) (Cialdini 1993). Three types of interactions among evacuees have been identified: $H B$ (i.e. following others' behaviour), cooperative behaviour (i.e. working or acting together for the common/mutual benefit) and competitive/selfish behaviour (Heliövaara et al. 2012; Pan 2006; Helbing et al. 2000).

This work focuses on the occurrences of HB during exit choice. HB occurs whenever a decision-maker prefers, among different options, to follow other people's choices (Banerjee 1992; Heliövaara et al. 2012). As regards to the exit choice, this can be explained by the decision of the evacuee to choose an exit just because other evacuees had selected it, instead of striving to identify the exit that would provide them with the best evacuation conditions. The literature argues that HB could have both positive and negative effects depending on the evacuation conditions (Alavizadeh et al. 2008). In fact, it can lead to unwanted situations in highly crowded buildings, with limited visibility situations (i.e. heavy presence of smoke) or when exits are difficult to find (e.g. because evacuation paths are not well indicated) causing damage to transportation systems and loss of life during evacuations since it could lead to a non-optimized use of the exits (Helbing \& Johansson 2011; Schadschneider et al. 2009; Alavizadeh et al. 2008; Saloma \& Perez 2005). However, it may help evacuees exit faster when the building is not highly populated and when evacuees are mostly unfamiliar with exit paths (Alavizadeh et al. 2008; Kirchner \& Schadschneider 2002). In fact, the choices made by evacuees familiar with the building could positively affect the choices of unfamiliar evacuees. Therefore, a full understanding of this behaviour can be indispensable to improve the evaluation of safety condition of transportation systems and buildings.

This paper presents a study of the decision-making process underpinning exit choice by using data collected through an online survey. The research consists of two steps: in the first step, a conceptual framework of $\mathrm{HB}$ is derived by reviewing the existing theories on social interaction. The outcomes of the review are used to make sense of the experimental results. In the second part, a stated preference experiment is carried out by asking participants to select an exit in relation to several hypothetical situations presented in short videos. A behavioural model based on the Random Utility Theory (RUT) is proposed to explain the occurrence of HB. A small qualitative study is performed to confirm the validity of the researchers' interpretation of the survey. The RUT has already been used to investigate exit choice and route choice in normal (Hoogendoorn \& Bovy 2004) and emergency situations (Guo \& Huang 2010; Guo \& Huang 2011; Lovreglio, Borri, et al. 2014; Guo et al. 2013). In these previous studies, the goal was to identify the exit or the route selected by pedestrians/evacuees considering 
the utility associated with each available exit/route. By contrast, this work aims at identifying the evacuees' utility to select the most crowded exit manifesting HB. This goal is achieved showing that $\mathrm{HB}$ can be the outcome of a rational decision-making process contrary to the Irrational Paradigm adopted by several existing models (Helbing et al. 2002; Kirchner \& Schadschneider 2002) and that both environmental and personal factors can influence the occurrence of this behaviour.

The paper is outlined as follows: Section 2 presents a review regarding the SIT and the SPT and how these theories can explain the occurrences of HB. A summary on the modelling approaches used so far to model HB is provided in Section 3. Then, the proposed approach is presented and compared with existing ones. The methodology adopted is described in detail in Section 4. Section 5 reports a case study and the analysis of the data collected through the online survey. A qualitative analysis of face-to-face interviews, aiming to investigate the reasons, which made respondents choose the most crowded exit is also presented. A discussion of the estimated model, a sensitivity analysis and an implementation of the proposed model are provided in Section 6. Conclusions are presented in Section 7.

\section{Social Interaction and Herding Behaviour}

As reported in the literature, evacuees usually behave differently depending on whether they are alone or in a group (Pan et al. 2007; Braun et al. 2003). Previous studies found that the decision to evacuate a building or a transportation system (Nilsson 2009; Fridolf et al. 2013; Latane \& Darley 1968; Lovreglio, Ronchi, et al. 2015b), or exit choice (Lovreglio, Borri, et al. 2014; Kinateder 2012; Lovreglio et al. 2015) can be strongly influenced by the behaviour of other evacuees. In fact, evacuees can behave differently in accordance with their role during emergency egress (i.e the Role-rule Theory (Canter et al. 1980)) and whether they are experiencing this situation with other evacuees that are familiar to them (i.e. the Affiliative Theory (Sime 1983)).

The following section aims to investigate how the SIT and the SPT can provide interesting insights on HB. The SIT was introduced in safety science by Nilsson and Johansson (Nilsson \& Johansson 2009) to explain the social interactions among evacuees. According to this theory, two types of social influences exist. One refers to people who are afraid of standing out by not complying with prevalent social norms, they try "to conform to the positive expectations of another" and so they are subject to the so called Normative Social Influences (NSIs) (Deutsch \& Gerard 1955; Nilsson \& Johansson 2009). The Informational Social Influences (ISIs) refer to those arising when an individual accepts "information obtained from another as evidence about reality" (Deutsch \& Gerard 1955).

Cialdini's SPT argues that "we view a behaviour as more correct in a given situation to the degree that we see others performing it" (Cialdini 1993). The SPT is directly related to the ISI. In fact, it implicitly assumes that the acts/choices of other people provide an external cue that could influence the decision-making process.

These two theories could help define some reasons that lead people to manifest HB. According to SIT, actions and choices made by others may be a source of information to understand what is going on during situations characterized by uncertainty (Kinateder 2012; Pan 2006). For instance, during exit 
choice, a decision maker can understand that an exit is available for escape because other evacuees are already heading towards it (Figure 1). A decision-maker exposed to others' actions might choose among different objectives/actions following others' behaviours. In exit choice, this means that a decision-maker chooses the most crowded exit. According to existing theories, two reasons can be provided to explain this behaviour. A decision-maker may choose the most congested exit just because he/she trusts the majority of other occupants' behaviour considering it as the right one (SPT). Another interpretation may be that he/she is concerned about being judged by others and prefers to avoid embarrassment due to a counter-current choice (NSI) (Figure 1). As reported in the literature, both the preference to trust in the majority's behaviour (SPT) and the fear to look foolish (NSI) are triggered by the uncertainly of the context of choice (Nilsson 2009; Pan 2006; Cialdini 1993). In addition, Cialdini argues the trust in the majority's behaviour may also occur when people are unsure of themselves (i.e. lack of self-confidence) (Cialdini 1993).

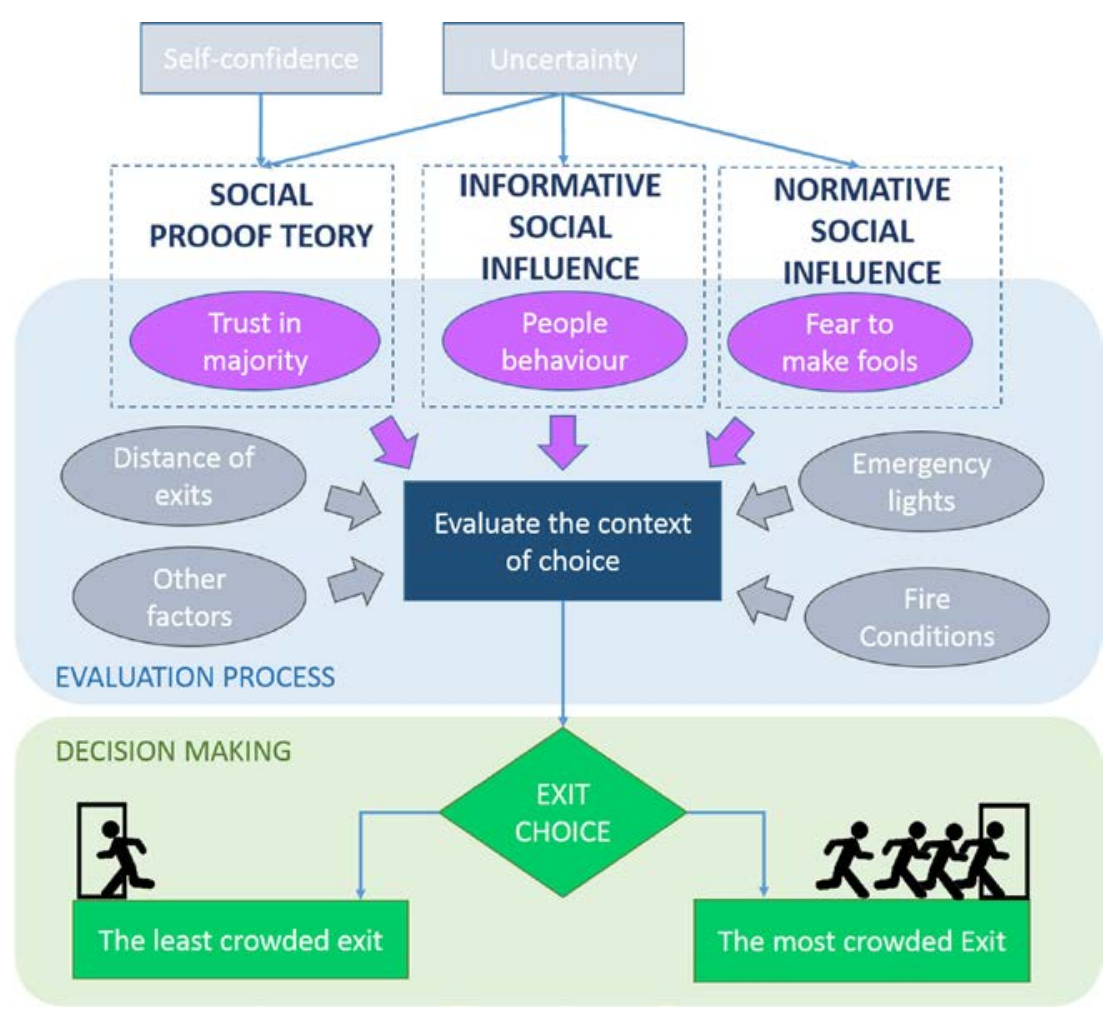

Figure 1 - Social Influences in exit choice

Therefore, it is possible to argue that the choice to herd can be result of a rational decision (i.e. a choice "procedurally reasonable in light of the available knowledge and means of computation") (Simon 1986; Lovreglio et al. 2015) instead of an irrational decision due to the 'panic' as proposed by several existing models (Helbing et al. 2002; Kirchner \& Schadschneider 2002). In fact, a decisionmaker living an ambiguous situation tries to find a trade-off between the possibility to choose the less crowded exits (which could allow a faster evacuation by taking the risk to make a counter-cultural choice) and the most crowded exit by trusting in the majority's behaviour. Then, the degree of uncertainty can make the difference in the choice since the higher the uncertainty the more decisionmaker could manifest $\mathrm{HB}$.

\section{Modelling approaches for HB}


Several evacuation models have been developed in the last few decades (Kuligowski et al. 2010; Gwynne et al. 1999). However, HB is simulated only in some of these models. Some of these models consider HB as a general behaviour always affecting evacuees (see, for instance, cellular automata models (Lovreglio, Ronchi, et al. 2015c; Guo et al. 2012; Schadschneider 2001; Burstedde et al. 2001; Guo et al. 2013)) whereas others assume that occurrences of HB can vary during evacuations depending of several factors. Assuming that HB is always present is a reasonable assumption, even though it is arguable that occurrences of this behaviour are constant during evacuations having different conditions. Different authors provided formulations to explaining what could affect the occurrence of HB during evacuations. Helbing et al. $(2000 ; 2002)$ include HB in their social forces models. In particular, the authors model HB vs. individualistic behaviour based on the degree of panic of the decision-maker. A similar approach (based on deterministic parameters related to agents' level of panic) is also used by Kirchner and Schadschneider (2002), Toyama et al. (2006) and Nishinari et al. (2006) in their cellular automaton models. Pan et al. (2007) presented a rule-based approach in their agent-based model. According to Pan et al. (2007), agents can behave as a herd by following this set of three behavioural rules: (1) random walk until a goal is detected, (2) if multiple goals are detected, compute the 'popularity' for each goal by observing other agents, and then choose the goal that has the biggest crowd, and (3) seek the goal. Differently, Korhonen (2011) defines a specific class of agents called "Herding agents". These agents follow a "conservative" strategy when available familiar exits are present; otherwise they behave on the basis of a herding strategy. Moreover, a HB effect is observed in the lattice gas model proposed by Isobe et al. (2004) to simulate evacuations from a room without visibility. According to the authors, the herding effect is the product of direct acoustic interactions. Another interesting approach, used to model HB, is based on fuzzy theory proposed by Dell'Orco et al. (2014). According to this model, the agents start becoming less independent and follow the surrounding people as panic increases. Altshuler et al. (2005) studied HB by using experiments with ants and then proposed a computer model in which the key-parameter is the "panic parameter". Finally, Saloma and Perez (2005) propose a two-parameter cellular automaton model from the study of mice. This model includes both a "panic threshold" parameter and an independent parameter called "imitation tendency".

The main weakness of the models investigating the variability of $\mathrm{HB}$ occurrences is that they assume that these occurrences are related only to the state of the agents and in particular to their panic state. However, many studies on human behaviour in fire and crowd disasters have showed that even under extremely critical conditions people do not panic but they behaved quite rationally helping each other (Helbing \& Mukerji 2012; Fahy et al. 2012). Fahy et al. (2012) argue that there is a misconception regarding the concept of panic among researchers and that the occurrences of it are very rare during fires. Moreover, Canter et al. (1980) state that there is no need to refer to the panic explanation to give an overview of what happened during emergencies but rational explanations can be used. The second weakness relies on those models not including the influences of personal (i.e. gender, age, occupation, etc.) and environmental (i.e. number of evacuees close to the exit or the decision-maker) variables on HB. Another weakness of these herding models is that all of them are deterministic and thus cannot model the randomness behind human behaviour in fire (i.e. behavioural uncertainty) (Ronchi et al. 2013; Lovreglio, Ronchi, et al. 2014) whereas the randomness is taken into account by the models assuming HB as a general behaviour (Lovreglio, Ronchi, et al. 2015c; Guo et al. 2012; 
Schadschneider 2001; Burstedde et al. 2001). The last shortcoming of the existing herding models is that these are not regression models from data collected during real emergencies or experiments.

Differently from the existing approaches, this work aims to model HB during exit choice by using the RUT. In fact, the decision to choose the most crowded exit (showing HB) can be defined as a discrete choice. Therefore, two utility functions can be defined for the two available possible choices (i.e. choice of the most crowded exit and choice of one of the other exits). Since these utilities include both a deterministic and a random part it is possible to estimate only the probability that a decision-maker chooses one alternative among the available ones (Ortuzar \& Willumsen 2011). A key assumption of this modelling approach is that the decision-maker behaves rationally by choosing the option with the higher utility function (Ortuzar \& Willumsen 2011; Train 2009). This assumption is confirmed with what is assumed in the previous section (i.e. HB is the result of a rational decision-making process) and with the existing literature (Canter et al. 1980). A full explanation regarding the remaining assumptions defining this modelling approach and its formulations is provided in (Ortuzar \& Willumsen 2011; Train 2009; Hensher et al. 2005).

The proposed approach differs from the existing one for many reasons. Firstly, the existing models assume that $\mathrm{HB}$ is directly related to the panic level of an agent according to "the more the panic level, the more an agent shows $\mathrm{HB}^{\prime \prime}$. Differently, the proposed model assumes that $\mathrm{HB}$ is the result of a rational decision-making process and both environmental and personal variables can influence the probability of the occurrences of HB. Then, the probabilistic approach offered by the RUT is a valid alternative to the deterministic one since it allows modelling behavioural randomness (i.e. behavioural uncertainty) related to discrete choice (Lovreglio, Ronchi, et al. 2014; Lovreglio et al. 2015). Moreover, another strength of the RUT is that it is possible to calibrate directly the model by using data collected through stated preferences (i.e. survey) or revealed preferences (i.e. real or experimental evacuations) (Ortuzar \& Willumsen 2011). Therefore, this modelling approach allows statistically testing the influences of different environmental and personal factors on the probability of having HB during exit choice.

In this work, data from stated preferences are used to show the potentials of the proposed approach. In fact, the proposed model is a regression model based on data collected by an online survey from 221 respondents (see Lovreglio, Borri et al. (2014) for more information regarding this survey).

The methodology used to estimate a new logit model is provided in the following section.

\section{Methodology}

The previous sections showed how $\mathrm{HB}$ could be the result of a rational decision-making process and the RUT can be a valid alternative to model HB during exit choice.

The methodology used in this work, to develop a new herding model, is divided into three main consecutive steps: Preliminary Analysis, Qualitative Analysis, and Modelling and Behavioural Analysis (Fig. 2).

In the first step, an analysis of data collected by Lovreglio, Borri et al. (2014) using an online survey was done to check whether respondents chose the most crowded exit in the proposed hypothetical 
scenarios. Data showed that in several cases respondents chose this option. However, at this stage, it was not possible to state that this behaviour is an instance of HB since other factors could make respondents choose the most crowded exit.

Therefore, in the second step, a new survey was made by using the same questionnaire and combined with a final face-to-face interview to investigate whether HB was the reason behind the choice of the most crowded exit. Additionally, these interviews allowed investigating whether social influences argued in Section 2 (i.e. ISI, NSI, SPT) could explain the behaviour of people choosing the most crowded exit.

The third step dealt with modelling and behavioural analysis. The goals of this step were to determine which model better fits the data and to provide a behavioural analysis of the proposed model. Moreover, some pieces of information collected during the second step were used to interpret the proposed model.

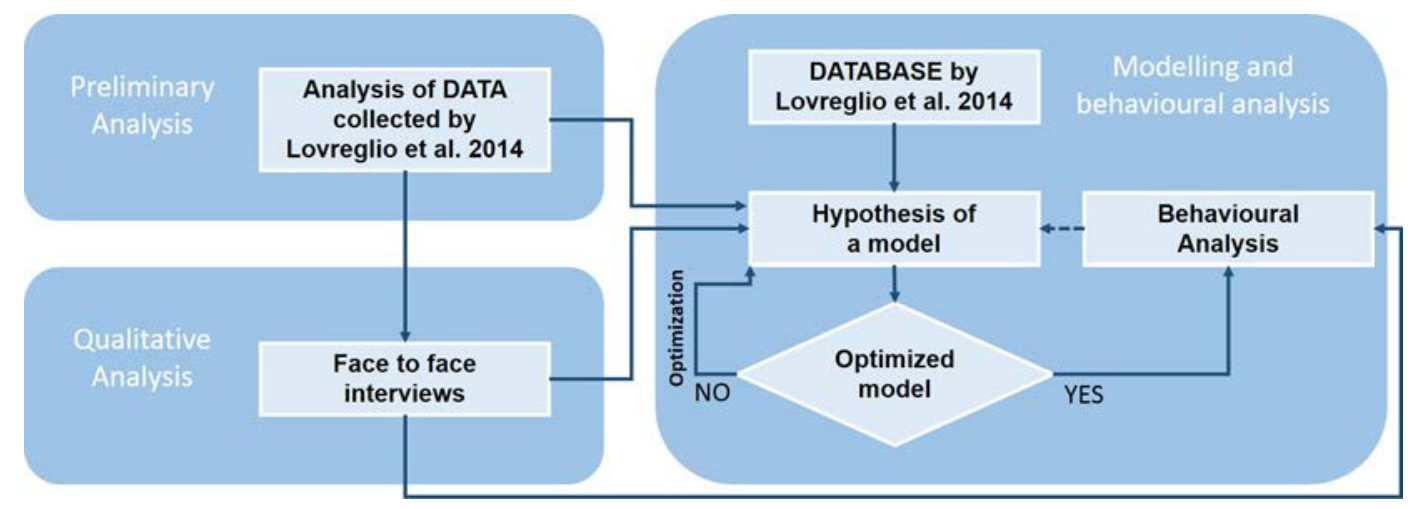

Figure 2 - Methodological scheme

\section{Case Study}

The data used in this work deal with stated exit choices for different hypothetical scenarios representing an enclosed environment, during emergencies, collected using an online survey. The goal of this survey was to study the influences of several variables on exit choice during emergencies. A previous exit choice model using this data is proposed in Lovreglio, Borri et al. (2014), this model demonstrated the influence of different variables on exit choice during emergencies.

Differently, this work aims to use the same dataset to study/model the occurrences of HB in exit choice. This data includes stated preferences provided by 221 respondents (191 coming from a previous survey (Lovreglio, Borri, et al. 2014) and 30 respondents from the new survey). Information about the recruiting of respondents and where the respondents come from are provided in Lovreglio, Borri et al. (2014). All these respondents were asked to state their preference between two exits for twelve different hypothetical scenarios administered using twelve different videos (see Video 1 for some examples of hypothetical scenarios). These hypothetical scenarios were selected by using an orthogonal design considering the following variables and levels (Lovreglio, Borri, et al. 2014):

- the Position of the Decision-Maker (PDM $=\{\mathrm{L}$ : Left; C: Center; R: right $\}$ ).

- the Number of People close to the two Exits (NPE $=\{0 ; 5 ; 10 ; 20\})$. 
- the Number of People close to the Decision-Maker (NPDM $=\{0 ; 1 ; 4 ; 8\}$ ).

Figures 3 and 4 illustrate graphically the context of choice.

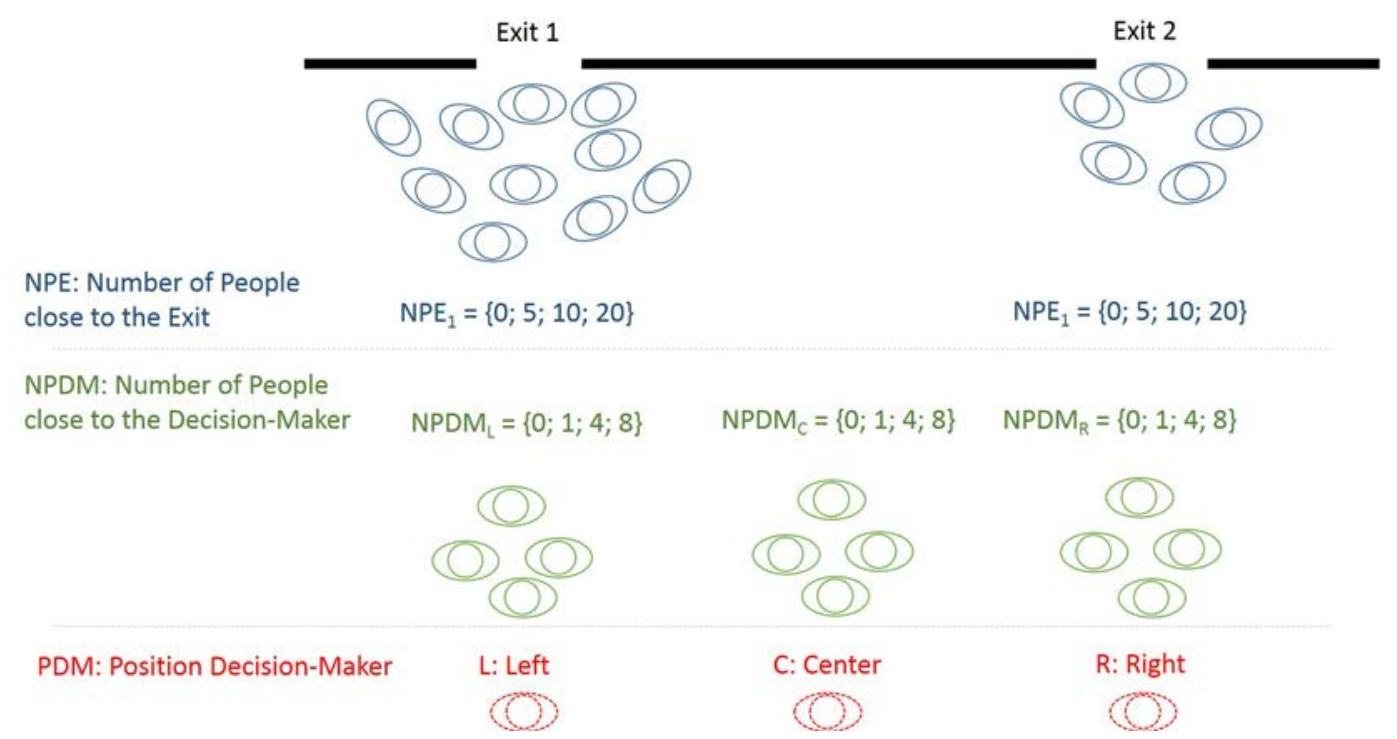

Figure 3 - Scheme of the context of choice

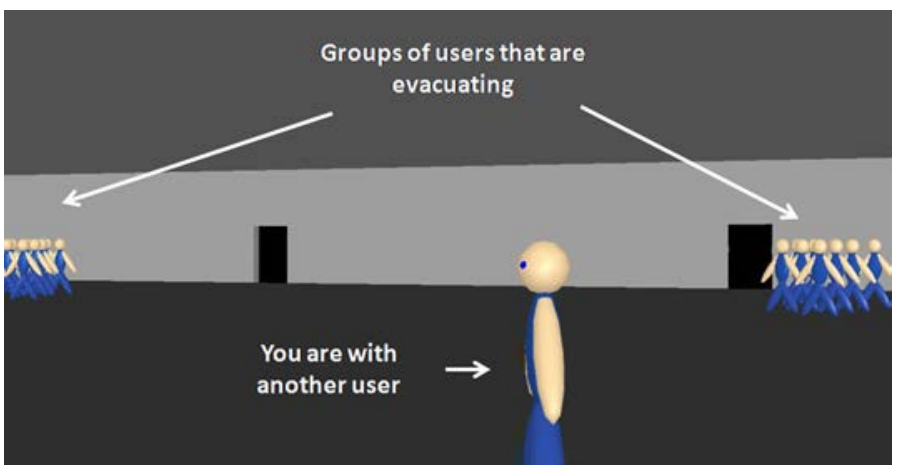

Figure 4 - View of the context of choice (frame taken from one of the videos showing a hypothetical scenarios)

Demographic data about respondents were also collected during this survey. The main demographic information regarding respondents are listed below:

- $33 \%$ female and $67 \%$ male;

- The median age is 24 , whereas the quartiles are 23,24 , and 26 respectively.

- The majority of respondents declared to be students (77\%);

- The education level of the sample is medium-high: $62 \%$ of the sample had graduated and $35 \%$ of the sample stated they had finished high school.

This work includes the same limitations introduced in Lovreglio, Borri et al. (2014). The main limitation is the impossibility to recreate a real scenario using an online survey. In fact, this technique does not allow for reproducing the situation of stress typically found during emergencies. Therefore, the model proposed in this work is not able to study the influence of stress levels and levels of nervousness on the occurrence of HB. Moreover, the sample used in this study is quite homogeneous (most of respondents are students). In fact, a heterogeneous sample may allow a better understanding of how 
personal variables influence the problem. Another limitation of the survey is that the data could be biased by the order of the proposed scenarios. In fact, it can be argued that the training process could influence the choices after the first scenarios. In this work, the order in which the hypothetical scenarios are proposed is shown in Table 1. A solution to reduce the spread of this effect can rely on the reduction of the number of scenarios for each respondent and on the randomized sequences of the scenarios. Therefore, the influence of the order of the hypothetical scenario needs to be investigated in future studies.

\subsection{Preliminary Analysis}

This analysis begins from the analysis of the results of the model estimated in Lovreglio, Borri et al. (2014). This model is a random parameter logit predicting the probability of choosing an exit considering different variables (see Ortuzar \& Willumsen (2011) for further information concerning random parameter logit). One of the estimated random parameters is the one associated with the number of people near the two exits (pNPE). Figure 5 shows the probability density function (PDF) of this parameter. This PDF shows that NPE is not perceived only as a disutility since there are positive values of pNPE with a relatively high probability (i.e. the presence of people close to an exit can increase the probability of a decision-maker to choose it). This means that in several cases respondents chose the most crowded exit. A further analysis is made using the data collected by the survey.

The survey includes 12 choices scenarios; different numbers of people near to the two exits are reported only in 10 scenarios (see the $4^{\text {th }}$ and $8^{\text {th }}$ scenarios in Table 1 ). Thus, respondents have the possibility to choose the most crowed exit 10 times. Table 1 shows how many respondents chose the most crowded exit for each scenario. Table 1 highlights that the most crowded exit is chosen in some scenarios more often than in others (e.g. see percentage of scenario 1 and scenario 5). This implies that a HB model should include environmental variables describing the context of choice.

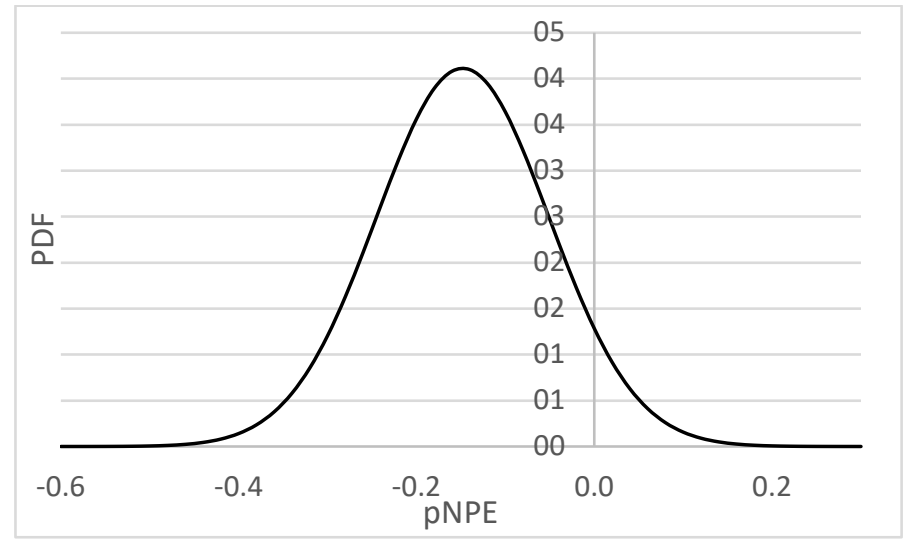

Figure 5 - Probability Density Function (PDF) of parameter associated to number of people near the two exits (pNPE)

Table 1 - Exit choice scenarios (NPE: number of people near exit 1 and 2; NPDM: number of people near decision maker; DM: decision maker; MCE: the most crowded exit; L: left; R: right; C: centre)

\begin{tabular}{|c|c|c|c|c|c|c|c|}
\hline Scenarios & $\begin{array}{c}\text { NPEE } \\
\text { xit1 }\end{array}$ & $\begin{array}{c}\text { NPEE } \\
\text { xit2 }\end{array}$ & NPDM & $\begin{array}{c}\text { DM } \\
\text { Positions }\end{array}$ & $\begin{array}{c}\text { N respondents who } \\
\text { choose MCE }\end{array}$ & Percentage & Block \\
\hline
\end{tabular}




\begin{tabular}{|c|c|c|c|c|c|c|c|}
\hline 1 & 0 & 5 & 1 & $\mathrm{~L}$ & 75 & $34 \%$ & $\mathrm{~A}$ \\
\hline 2 & 20 & 10 & 1 & $\mathrm{R}$ & 46 & $21 \%$ & $\mathrm{~A}$ \\
\hline 3 & 0 & 10 & 4 & $\mathrm{C}$ & 57 & $26 \%$ & $\mathrm{~A}$ \\
\hline $4^{*}$ & 10 & 10 & 0 & $\mathrm{~L}$ & - & - & - \\
\hline 5 & 20 & 5 & 4 & $\mathrm{C}$ & 34 & $15 \%$ & $\mathrm{~A}$ \\
\hline 6 & 0 & 20 & 8 & $\mathrm{R}$ & 50 & $23 \%$ & $\mathrm{~A}$ \\
\hline 7 & 10 & 20 & 1 & $\mathrm{C}$ & 45 & $-20 \%$ & $\mathrm{~A}$ \\
\hline $8^{*}$ & 5 & 5 & 0 & $\mathrm{R}$ & - & $20 \%$ & $\mathrm{~A}$ \\
\hline 9 & 10 & 5 & 8 & $\mathrm{C}$ & 45 & $20 \%$ & $\mathrm{~B}$ \\
\hline 10 & 5 & 20 & 4 & $\mathrm{~L}$ & 44 & $25 \%$ & $\mathrm{~B}$ \\
\hline 11 & 5 & 0 & 1 & $\mathrm{C}$ & 55 & $26 \%$ & $\mathrm{~B}$ \\
\hline 12 & 10 & 0 & 4 & $\mathrm{R}$ & 57 & & \\
\hline
\end{tabular}

Table 2 shows how many respondents chose the most crowded exit for $n$ times $(n=0, \ldots, 10)$. No respondents chose the most crowded exits all 10 times, while 2 respondents chose the exit 9 times and so on. Some respondents have preferred, several times, the most crowded exit, while a large part of respondents chose the most crowded exits for 3-0 times. Therefore, Table 2 shows that respondents manifest different herding attitudes. This points out that it is possible to segment respondents in different herding classes to study the behavioural differences among these classes.

Table 2 - Number of times in which the most crowded exit was chosen by the same respondent

(NoT) vs. Number of respondents who choose the most crowded exit for NoT times (NoR) (P: percentage; CP: Cumulative Percentage)

\begin{tabular}{|c|c|c|c|c|c|c|c|c|c|c|c|}
\hline NoT & 10 & 9 & 8 & 7 & 6 & 5 & 4 & 3 & 2 & 1 & 0 \\
\hline NoR & 0 & 2 & 3 & 7 & 10 & 8 & 25 & 32 & 36 & 51 & 47 \\
\hline P (\%) & 0 & 0.9 & 1.4 & 3.2 & 4.5 & 3.6 & 11.3 & 14.5 & 16.3 & 23.1 & 21.3 \\
\hline CP (\%) & 0 & 0.9 & 2.3 & 5.4 & 10 & 13.6 & 24.9 & 39.4 & 55.7 & 78.7 & 100 \\
\hline
\end{tabular}

The next step of this work is to understand why and when respondents chose the most crowded exit and if this behaviour can be labelled as HB. Thus, a qualitative analysis based on face-to-face interviews was made to answer these questions.

\subsection{Qualitative Analysis: face-to-face interviews}

A supplementary survey was carried out with 30 volunteers which filled out the same survey used in Lovreglio, Borri, et al. (2014). Actually, 16 of these volunteers filled out the survey after the deadline of the study proposed in Lovreglio, Borri, et al. (2014); therefore, this data was not included in their previous analysis but was included in this new study. The authors contacted the remaining 14 volunteers by asking them to fill out a survey and to be interviewed afterwards. The main aim of these interviews was to investigate the reason that lead respondents choosing the most crowded exit to understand if that was HB. Therefore, the small number of interviews is not relevant for the scope of this work. 
These respondents were recruited from the same sample analysed in Lovreglio, Borri, et al. (2014) (see Section 5) and were asked to meet one of the authors one by one. After that, the author made him/her fill out the survey on a laptop. Once the survey was ended, the author started interviewing the respondent. During these interviews, the volunteers were asked about the strategy they adopted for their choices, the factors that influenced their choices and general perception of the scenarios.

The main two strategies stated by the interviewees were:

- Strategy A: I have chosen the least crowded exit to evacuate as soon as possible;

- Strategy B: I have chosen the most crowded exit to evacuate with the majority of evacuees (i.e. HB).

The results of these interviews are displayed in Table 3, which shows how many interviewees stated to choose strategy A or B as their main strategy.

Table 3 - Results of the interviews

\begin{tabular}{|l|c|c|c|c|c|c|}
\hline & $\begin{array}{c}\text { Strategy } \\
\text { A }\end{array}$ & $\begin{array}{c}\text { Strategy } \\
\text { B }\end{array}$ & $\begin{array}{c}\text { Other } \\
\text { Strategy }\end{array}$ & ISI & NSI & SPT \\
\hline $\mathrm{N}^{\circ}$ of interviewee & 8 & 5 & 1 & 6 & 0 & 7 \\
\hline Percentage & $57 \%$ & $36 \%$ & $7 \%$ & $43 \%$ & $0 \%$ & $50 \%$ \\
\hline
\end{tabular}

As can be seen in Table 3 the majority of interviewees followed strategy A. This is in accordance with Table 2 (only $24.9 \%$ of respondent chose the most crowded exit more than 3 times). However, there are some respondents that followed strategy B showing HB.

Table 3 includes also the number of people interviewed, who justified their own behaviours by using instances of both the SIT and the SPT. Respondents who followed strategy B, stated that this is due to the uncertainty related to the situation of choice. This uncertainty was due to the absence of information about the places where the two doors lead (the two exits have no emergency light). Respondents tried to fill this gap (to understand if an exit is useful to evacuate) looking at the other evacuees involved in the hypothetical scenarios showing ISIs. Some respondents stated also that they chose the most crowded exit because they trusted in the choice of the majority according to the SPT. Then, some respondents who claimed to follow strategy A sometimes chose the most crowded exit when the least crowded one was completely empty exhibiting HB. They explained that this was due to their uncertainty on the usability of the empty exit. None of interviewees stated to avoid the least crowded exit because of fear to make a counter-cultural choice showing NSIs. This could be due to the fact that agents in the virtual environment could not see the respondent's choices. Finally, the majority of respondents, who stated to trust the information coming from the majority (SPT), stated also that they understood that an exit was available as emergency exit because others were using it (ISI).

Therefore, it is possible to argue that the interviews confirmed that HB played a role in exit choices and that $\mathrm{HB}$ is the main reason made respondents choose the most crowded exit. Therefore, in the following part of this work, the authors assume the choice of the most crowded exit as an instance of HB.

\subsection{Modelling}


According to what is reported in section 5.1, some respondents chose the most crowded exits more than other respondents did (see Table 2). This means that it is possible to define different herding classes. This is performed by dividing the dataset (made up of 12 scenarios, see Table 1 ) into two parts. The answers stated for scenario 4 and 8 are excluded since there is not the possibility to define the most crowded exit. The remaining 10 scenarios are split into two blocks as shown in Table 1 . The answers stated for the first seven scenarios (block $A$ ) are used to estimate the binary logit whereas the last three answers (block B) are used to define the herding classes.

The herding classes are defined according to the following rules:

- Respondents belonging to HC (High herding Class) are those who chose 2 or 3 times the most crowded exit;

- Respondents belonging to MC (Medium herding Class) are those who chose 1 time the most crowded exit;

- Respondents belonging to LC (Low herding Class) are those who chose 0 time the most crowded exit;

Therefore, all respondents belonging to $\mathrm{HC}$ showed the highest inclination towards $\mathrm{HB}$. On the contrary, respondents belonging to LC showed the lowest inclination.

Table 4 provides a brief description of all the respondents who belong to the three classes by taking into account the gender, occupation, and age.

Table 4 - Personal characteristics of the respondents for each class

\begin{tabular}{|c|c|c|c|c|}
\hline HB Class & Number of Respondents & Gender & Occupation & Age \\
\hline H & 45 & female:29\% & Student: $60 \%$ & Mean: 26.5 \\
\hline M & 55 & female:27\% & Student: $89 \%$ & Mean: 25.1 \\
\hline L & 121 & female:37\% & Student: $78 \%$ & Mean: 25.5 \\
\hline
\end{tabular}

A Chi-squared Test is used to verify if the herding aptitude is influenced by both gender and occupation. The Krukal-Wallis rank sum test is then used to verify if the samples of age of the four herding classes come from the same population.

Chi-squared Test shows that the null hypothesis (i.e. the variables are independent) can be rejected only for the occupation ( $p$-value $=0.00$ ) but not for the gender ( $p$-value $=0.34)$. Therefore, the herding attitude is dependent on the occupation.

Krukal-Wallis rank sum test shows the difference of age between populations to not be significant ( $p-$ value $=0.60$ ). Moreover, Figure 6 shows $\mathrm{HC}$ has a dispersion bigger than MC and LC.

At the end of this analysis, it is possible to say that the occupation is the only variable that influences the herding level while age and sex do not influence it. 


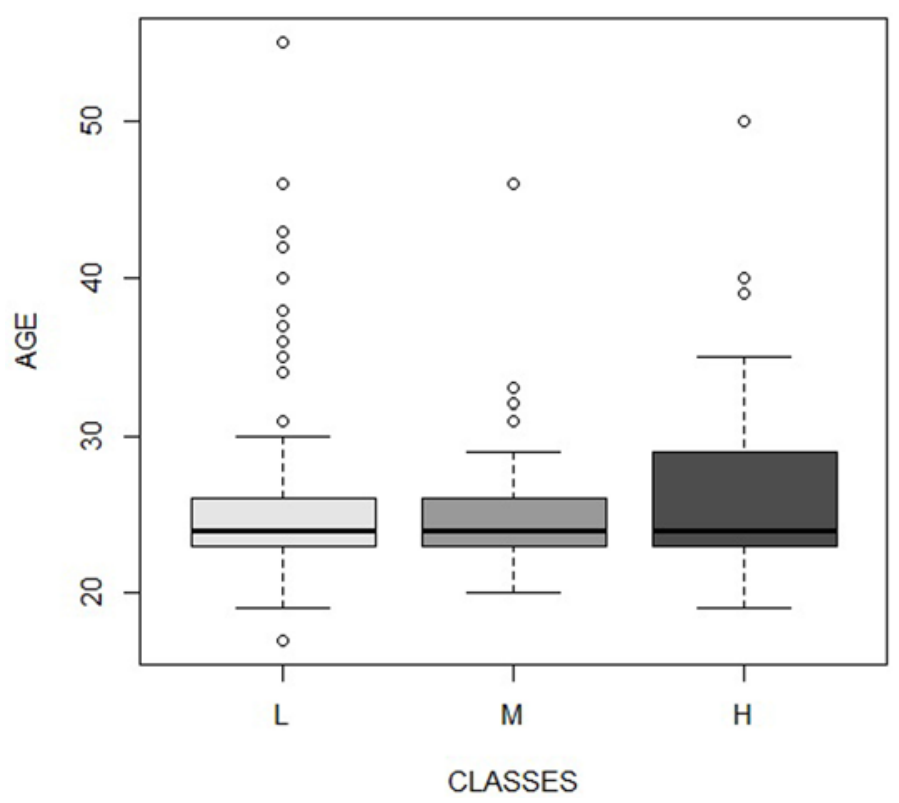

Figure 6 - Boxplots of the ages for the three herding classes (HB classes: HC: High Class; MC: Medium Class; LC: Low Class)

A binary logit is estimated to predict the occurrence of $\mathrm{HB}$ during exit choice. The dependent variable assumes a value of 1 if the most crowded exit is chosen instead of the least crowded one. The proposed model includes both environmental and personal variables as independent variables. Different model specifications were tested to find the one with better fitting and excluding variables not statically significant (i.e. stepwise regression). On one hand, the environmental variables tested in this study come from observations made by previous studies (Heliövaara et al. 2012; Nilsson 2009) arguing that social influences can have a strong impact on exit choice. After a focus group session was conducted by the authors, the final variables were chosen and tested in a previous study (Lovreglio, Fonzone, et al. 2014) which proves that these statistically affect herding behaviour in exit choice. On the other hand, the personal variables are all those collected during the survey (Lovreglio, Borri, et al. 2014). The variables eventually included in the proposed model are:

\section{ENVIROMENTAL:}

- DIF: difference between numbers of people close to the most crowded exit and the least crowded one;

- NPEMIN: number of people close to the least crowded exit;

- NPDE: number of people close to the decision maker;

PERSONAL:

- HIGH: height of decision maker;

- SEX: gender of the decision-maker (M: male; F: female);

- STUD: dummy variable, equal to 1 when decision maker states to be a student;

- HC_DV: dummy variable, that is equal to 1 when the decision maker belongs to the High Class;

- MC_DV: dummy variable, that is equal to 1 when the decision maker belongs to the Medium Class; 
A binary logit including herding classless is estimated and their parameters are shown in Table 5 . The deterministic part of the utility function related to the decision to choose the less crowded exits is set to zero whereas all the variables are included in the second utility function (i.e. the one associated to choice of the most crowded exit).

Table 5 - Binary Logit Models

\begin{tabular}{|c|c|c|c|c|}
\hline Model: & \multicolumn{2}{|c|}{ Binary Logit with Herding Classes } & \multicolumn{2}{|c|}{ Binary Logit without Herding Classes } \\
\hline Fitting & \multicolumn{2}{|c|}{$\begin{array}{c}\text { Log likelihood function }=-768.1862 \\
\text { RsqAdj }=0.28\end{array}$} & \multicolumn{2}{|c|}{$\begin{array}{c}\text { Log likelihood function }=-809.8934 \\
\text { RsqAdj }=0.24\end{array}$} \\
\hline Variable & Coeff. & P-value & Coeff. & P-value \\
\hline DIF & -0.030 & 0.027 & -0.022 & 0.098 \\
\hline NPEMIN ${ }_{F-S}$ & -0.091 & 0.002 & -0.087 & 0.002 \\
\hline NPEMIN $_{\text {F-NS }}$ & -0.134 & 0.021 & -0.059 & 0.182 \\
\hline NPEMIN $_{M}$ & -0.056 & 0.004 & -0.048 & 0.010 \\
\hline $\mathrm{HIGH}_{\mathrm{M}-\mathrm{S}}$ & -0.006 & 0.000 & -0.005 & 0.000 \\
\hline $\mathrm{HIGH}_{\mathrm{M}-\mathrm{NS}}$ & -0.004 & 0.013 & -0.001 & 0.449 \\
\hline $\mathrm{HIGH}_{\mathrm{F}}$ & -0.004 & 0.002 & -0.003 & 0.011 \\
\hline NPDM & -0.059 & 0.021 & -0.048 & 0.052 \\
\hline $\mathrm{H}_{\mathrm{M}-\mathrm{S}}$ & 1.438 & 0.000 & & \\
\hline $\mathrm{H}_{\mathrm{M}-\mathrm{NS}}$ & 1.299 & 0.000 & & \\
\hline $\mathrm{H}_{\mathrm{F}-\mathrm{S}}$ & 0.893 & 0.004 & & \\
\hline $\mathrm{H}_{\mathrm{F}-\mathrm{NS}}$ & 2.046 & 0.000 & & \\
\hline M & 0.483 & 0.002 & & \\
\hline
\end{tabular}

The introduction of the dummy variables (HC_DV, MC_DV) is an artifice used to differentiate the probability of occurrences of HB for respondents having different herding aptitude. In fact, in Section 5.1 it is pointed out that there are groups of respondents, who were more likely to show HB. As it is possible to expect, HC_DV and MC_DV are a positive constants increasing the probability of showing HB for those decision-makers who do not belong to LC.

A second binary logit not including herding classless is also estimated to investigate the improvement provided by HC_DV and MC_DV. This comparison points out that the herding classes improve the predictability of the model (see the fitting values in Table 5). Moreover, the herding classes improve the statistical significance of the parameters associated with some variables included in the model (see the p-values columns in Table 5). In fact, some parameters of the logit not including herding classes are not statistically significant whereas the proposed model (i.e. the one including herding classes) has all p-value smaller than 0.05 . It is plausible these parameters are not significant for collinearity issues that are solved segmenting the respondents' behaviours though the herding classes.

The model shows that the decision-making process is influenced by environmental and personal variables and combinations of them. Systematic variations in decision-maker tastes due to gender and occupation are observed. In fact, the estimated parameters can have different values according to whether the decision maker is male (subscript $\mathrm{M}$ ) or female (subscript $\mathrm{F}$ ), and student (subscript $\mathrm{S}$ ) or 
non-student (subscript NS). The model includes also a combination of this subgroup (i.e. M-S, M-NS, etc.). For instance, subscription F-S means that the decision-maker is a female student.

\section{Discussion}

The model proposed in this work allows predicting the probability that an evacuee manifests HB during exit choice. A preliminary description of the model can be done through the analysis of the signs of the estimated parameters and the use of a conceptual framework introduced in Section 2.

The model shows that the probability of having an occurrence of $\mathrm{HB}$ decreases with the increase of the difference between the number of persons close to the most crowded exit and the least crowded exit (DIF). Ultimately what this means is that when this difference is very high, a decision maker prefers the least crowed exit because the most crowded one could require high evacuation time. Therefore, this parameter seems to explain also the trade-off between the inclination to choose the quickest exit and the effects of uncertainty on the usability of the empty exit (i.e. respondents are not sure if it is an available exit). In fact, when DIF is very high, the benefits offered by the least crowded exit (i.e. quicker evacuation times) compensate the effects of the uncertainty that would lead the decisionmaker to choose the most crowded exit.

The model shows that also the number of people close to the least crowded exit influences the choice. The greater the number of people close to the least crowded exit, the lower the probability of exhibiting HBs. This trend is more evident for females (NPEMINF-(S or NS)> NPEMIN $N_{M}$ ) and among the female respondents for the non-student category (NPEMIN F-NS $>$ NPEMIN ${ }_{F-S}$ ). Therefore, the model highlights that occurrences of $\mathrm{HB}$ are more likely when there is any evacuee close to the least crowded exit. This may be due to the higher level of uncertainty associated with that option as observed during the interviews (see Section 5.2). This was also observed in a previous study reported in Lovreglio, Fonzone, et al. (2014). On the contrary, the presence of a significant number of people close to the least crowded exit (i.e. $2^{\text {nd }}$ scenario) may allow decision-makers to think that the exit is also available.

The model shows also that the number of people close to the decision maker (NPDM) reduces the probability of displaying HB toward people close to the exit. This can be explained by the fact that the decision-maker is already showing HB toward people close to him/her following the choice of people around them rather than that of the people close to the door. However, this hypothesis cannot be verified because persons who are near stand close to the decision maker and do not have a direction toward which they can move.

The model shows that decision-makers' personal variables influence directly the probability of $\mathrm{HB}$. In fact, the model shows that the probability decreases with the increase of decision-makers' height even though there are differences related to decision-makers' gender $\left(\mathrm{HIGH}_{\mathrm{M}-(\mathrm{S} \text { or NS) }} \neq \mathrm{HIGH}_{\mathrm{F}}\right)$ and between employment statuses $\left(\mathrm{HIGH}_{\mathrm{M}-\mathrm{S}} \neq \mathrm{HIGH}_{\mathrm{M}-\mathrm{NS}}\right)$. This means that taller people tend to avoid the most crowded exit. This tendency could be explained using the conceptual framework introduced in Section 2. In fact, according to the literature, height could be an indicator of the level of self-confidence (Booth 2010; Judge \& Cable 2004). Therefore, the shorter the decision-maker, the more a decision-maker trusts the choice of the majority choosing the most crowded exit.

Finally, the probability changes according to the decision-maker's classification into one of the three herding classes (HC, MC, and LC). The classes are defined according to the inclination to choose the 
most crowded exit. Therefore, the result is expected. Nevertheless, Table 5 shows that: (1) considering HB attitude improves the predictability of model; (2) there are significant differences between the classes, even after environmental and physical characteristics are controlled. Consequently, there is a latent factor (namely, herding aptitude) that characterizes decision-makers' exit choice. However, in this work, the only indicator of this latent factor is the amount of time a decision-maker takes to choose the most crowded exit. Further studies are needed to have a better understanding of this aptitude.

The following section describes a sensitivity analysis performed on the model to have a better understanding of the results.

\subsection{Analysis}

A sensitivity analysis is performed to show the influences of the different variables on the probability of $\mathrm{HB}$ in exit choice.

The influence of the herding classes defined in Section 5 is initially investigated. Figure 7 shows how the probability decreases with an increase in the difference between, numbers of people close to the most crowded exit and the least crowded one (DIF) for decision-makers belonging to different herding classes (i.e. LC, MC and HC). The four curves refer to a male student decision-maker with a height of $170 \mathrm{~cm}$. The curves show that the probability of HB changes within the different classes. These curves show how this model is able to differentiate the behaviour of decision-makers with different herding attitude. These curves are also compared with that of the model proposed in Lovreglio, Fonzone, et al. (2014) that shows an "average" single curve for all the decision makers. To highlight this comparison, the scale of DIF is twice that used to calibrate the model (i.e. maxDIF=20).

The combined effect of the difference of the number of persons close to the most crowded exit and the least crowded exit (DIF) and the number of people close to the least crowded exit (NPMIN) is shown in Figure 8. This surface is referred to a male student decision-maker with a height of $170 \mathrm{~cm}$. The surface shows that the probability of having an occurrence of HB decreases with both DIF and NPMIN. This means, for instance, that in a scenario with 20 people close to the most crowded exit and 10 people close to the least crowded exit the probability of observing HB is higher than in a scenario with 30 people close to the most crowded exit and 20 people close to the least crowded exit because of negative influence of NPMIN (see Table 5). However, it is important to underline that this surface shows results for a couple of independent variables (DIF, NPMIN) five times beyond the observed data (i.e. maxDIF=20; maxNPMIN=10). Therefore, a user of this model should be aware that these results could be different from the real behaviour, especially since data for bigger values of DIF and NPMIN are not available so far. 


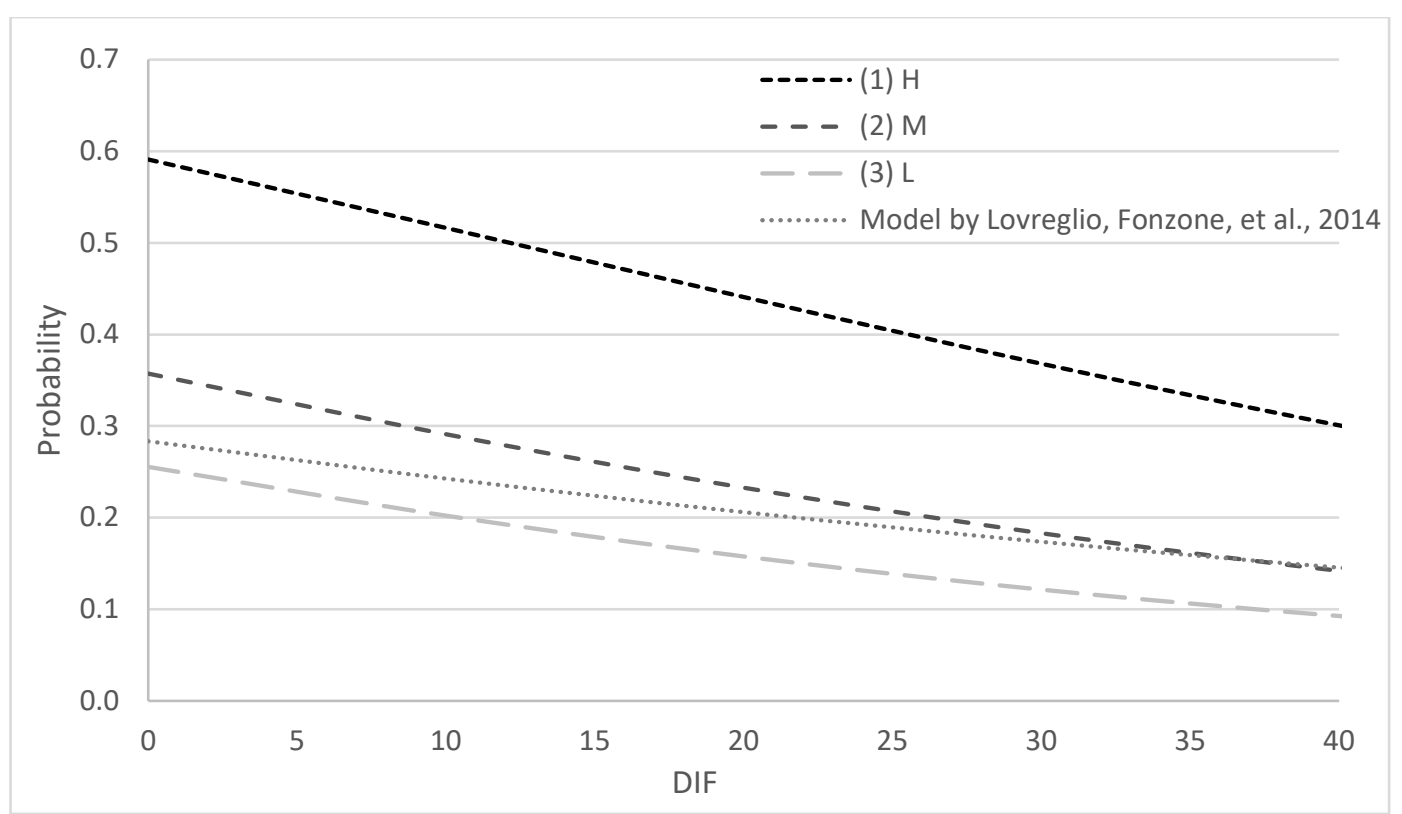

Figure 7 - Probability of a male student decision-maker with a height of $170 \mathrm{~cm}$ exhibiting HB (see Section 5 for the definition of HC, MC, and LC classes; DIF: difference between numbers of people close to the most crowded exit and the least crowded one; NPDE=NPEMIN=0).

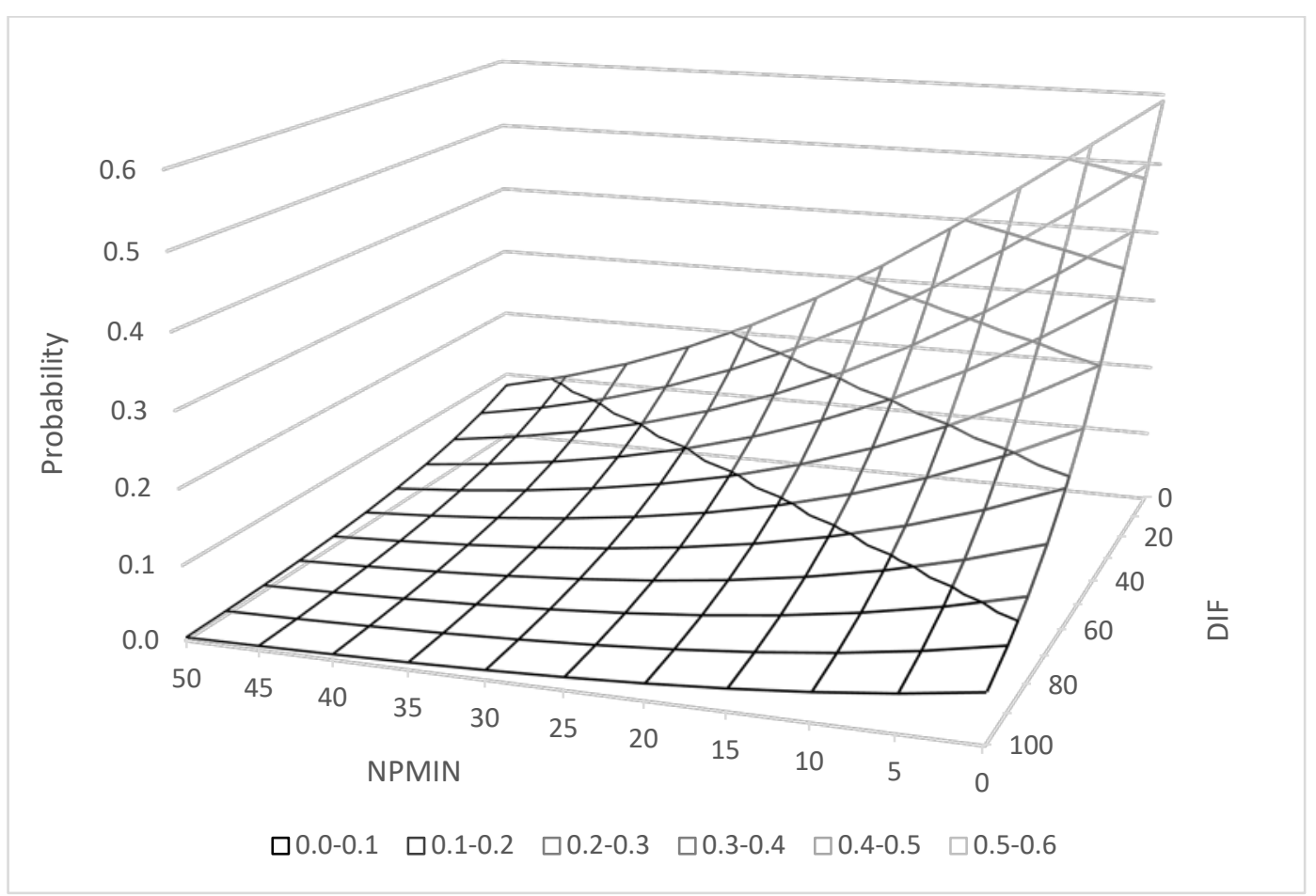

Figure 8 - Probability of a male student decision-maker with a height of $170 \mathrm{~cm}$ belonging to class $\mathrm{HC}$ exhibiting HB (see Section 5 for the definition of HC class; DIF: difference between numbers of people close to the most crowded exit and the least crowded one; NPMIN: number of people close to the least crowded exit; NPDM $=0$ )

\subsection{Simulation}


An implementation of the proposed model (i.e. the one including herding classes) has been made by using Unity3D to verify the predictability of the model. The geometry of the chosen scenario is shown in Figure 9. The scenario includes 30 agents that have to choose between two exits. In the proposed scenario, agents make an exit choice only once they pass through the first door on their path. Therefore, the environmental variables (i.e. DIF, NPEMIN and NPDE) are evaluated for each agent whenever it passes through the first door. Moreover, all the agents have same personal settings (gender: male; high $=170 \mathrm{~cm}$; no-student and belonging to the class high). Ten simulations have been run because the model is not deterministic and the outcomes of these simulations are proposed in Table 6 (Video 2 shows the first of these simulations). Table 6 shows that the doors are not used in the most efficient way. In fact, the maximum percentage (Max \%) is quite far from the optimum values (Max \% $\approx 50 \%$ ) for which half of the agents choose the right hand exit and the other half the left hand exit. Therefore, these simulations highlights that the proposed model can predict the creation of queues close to an exit due to HB.

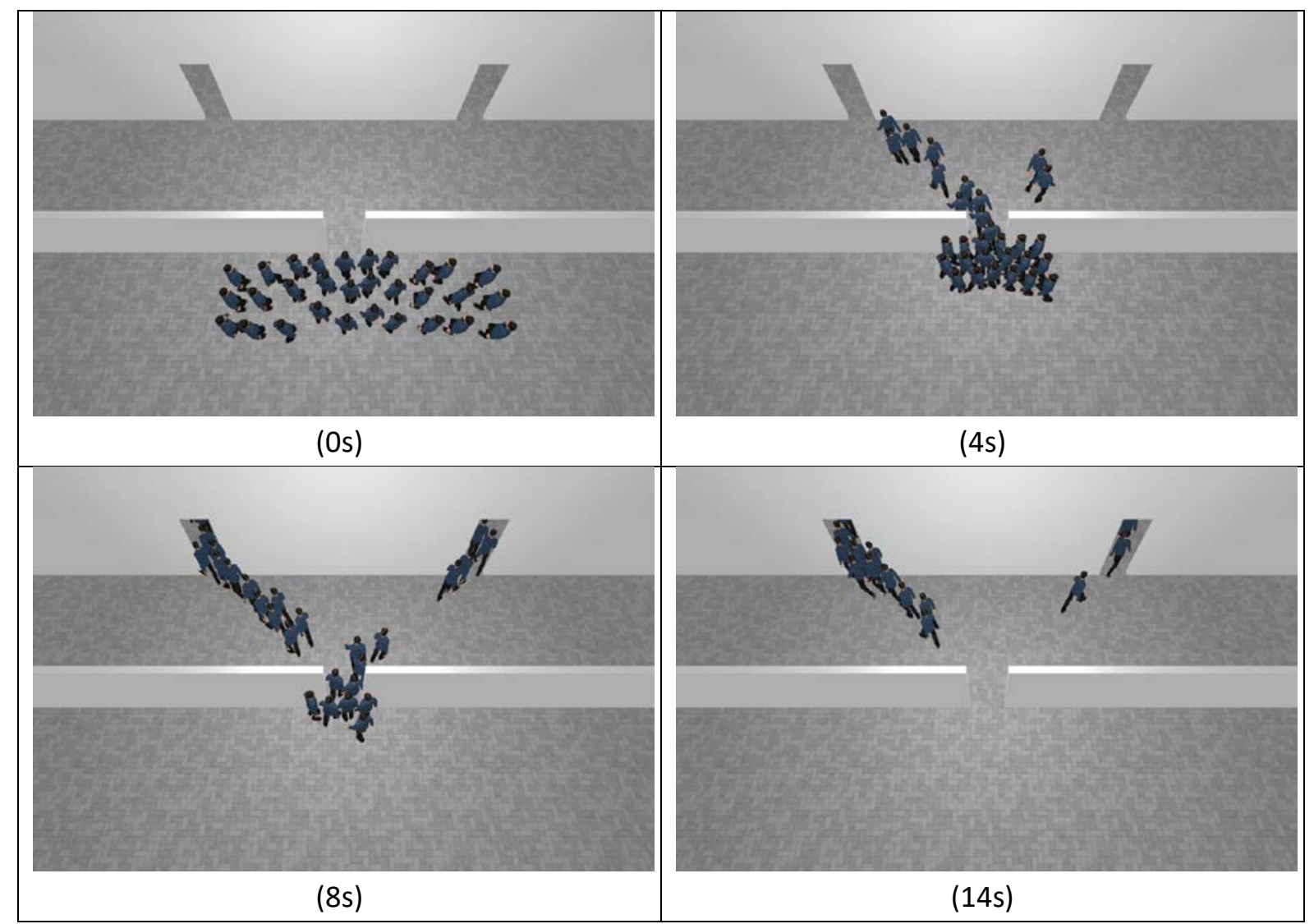

Figure 9 - Frames of the first simulation (see Table 6)

\section{Conclusion}

This work investigates the influence of HB in exit choice during emergencies. By using existing social theories, an explanation of this behaviour is proposed. The results of this research point out that both the SIT and the SPT can have a key role in explaining HB and prove that HB can be the result of a rational decision-making process instead of an "irrational-panic" decision. 
An overview of the existing approaches used to model HB has been made which underlines the weaknesses of these approaches. A new approach based on the RUT is proposed and compared with the existing ones.

Table 6 - Outcomes of simulation (LE: agents evacuated through the left hand exit; RE: agents evacuated through the right hand exit; Max \%: percentage of people who evacuate through the most crowded exit)

\begin{tabular}{|c|c|c|c|}
\hline Simulation & LE & RE & Max \% \\
\hline 1 & 23 & 7 & 77 \\
\hline 2 & 14 & 16 & 53 \\
\hline 3 & 17 & 13 & 57 \\
\hline 4 & 13 & 17 & 57 \\
\hline 5 & 22 & 8 & 73 \\
\hline 6 & 18 & 12 & 60 \\
\hline 7 & 20 & 10 & 67 \\
\hline 8 & 17 & 13 & 57 \\
\hline 9 & 16 & 14 & 53 \\
\hline 10 & 18 & 12 & 60 \\
\hline
\end{tabular}

This new approach is applied using the data collected in Lovreglio, Borri, et al. (2014) through an online survey aimed to investigate exit choices during emergencies. A behavioural model allowing the prediction of the occurrences of HB in exit choice is proposed. The results of this model are different from the existing models for different reasons. Firstly, the proposed model shows that both environmental variables and personal ones affect the probability of occurrences of HB in exit choice. Differently, most of the existing models confirm that $\mathrm{HB}$ is only related to the panic level of the decision-maker. Secondly, the proposed model allows modelling the randomness characterizing human behaviour in fire (i.e. behavioural uncertainty). Furthermore, the proposed model is dataoriented since it was estimated by using data collected by 221 different decision-makers.

The proposed work underlines the existence of different aptitudes to herd among the respondents, which in turn influences the probability of occurrences of HB in exit choice. In this work, the herding classes shown in Table 1 are defined using the number of times the most crowded exit was chosen by each respondent. Therefore, the development of a future new model could be useful to define herding aptitude (seen as a latent factor) using the decision-makers' personal variables and new indicators of this latent factor (Lovreglio et al. 2015).

Finally, from a modelling point of view, the proposed model investigates HB for scenarios having only two exits in an environment without any obstacle. This is due to the nature of data used to calibrate of the proposed model (i.e. hypothetical scenarios defined in Lovreglio, Borri, et al. (2014)). However, the RUT can also provide a modelling solution for more complex situations including more than two exits (using, for instance, the multinomial formulation (Train 2009; Hensher et al. 2005)) and other factors affecting the choice (such as obstacles that can limit evacuees' visibility). The main issue to estimate models for more complex scenarios is still the availability of actual evacuations or experimental data. Therefore, future research is necessary to collect new data in which evacuees have to face more complex hypothetical scenarios. This could be done by performing new stated or 
revealed preference studies through the use of new immersive or non-immersive virtual reality technologies (Ronchi et al. 2015; Lovreglio, Ronchi, et al. 2015a).

\section{Acknowledgements:}

The authors thank Brett Done, Dr. Elisabetta Carattin (ARUP) and Waleed Shoaib (Lund University) for proofreading this work. Ruggiero Lovreglio thanks Dr. Lucia Ballerini (The University of Edinburgh) for her suggestions and comments.

\section{References}

Alavizadeh, F., Moshiri, B. \& Lucas, C., 2008. Application of Naturalistic Decision Making to Emergency Evacuation Simulations. In J. Darzentas et al., eds. Artificial Intelligence: Theories, Models and Applications. Lecture Notes in Computer Science. Berlin, Heidelberg: Springer Berlin Heidelberg, pp. 14-25.

Altshuler, E., Ramos, O. \& Nunez, Y., 2005. Symmetry breaking in escaping ants. The American Naturalist, 166(6), pp.643-649.

Averill, J.D. et al., 2005. Federal Building and Fire Safety Investigation of the World Trade Center Disaster: Occupant Behavior, Egress, and Emergency Communications.

Banerjee, A. V., 1992. A Simple Model of Herd Behavior. The Quarterly Journal of Economics, 107-3, pp.797-817.

Booth, N.D., 2010. The Relationship between Height and Self-Esteem and the Mediating Effect of Self-Consciousness. The Journal of Social Psychology, 130(5), pp.609-617.

Braun, A. et al., 2003. Modeling individual behaviors in crowd simulation. In Proceedings 11th IEEE International Workshop on Program Comprehension. IEEE Comput. Soc, pp. 143-148.

Burstedde, C. et al., 2001. Simulation of pedestrian dynamics using a two-dimensional cellular automaton. Physica A: Statistical Mechanics and its Applications, 295(3-4), pp.507-525.

Canter, D., Breaux, J. \& Sime, J., 1980. Domestic, multiple occupancy, and hospital fires. In D. Canter, ed. Fires and Human Behaviour. Jhon Wiley and Sons, pp. 117-136.

Cialdini, R., 1993. Influence: The Psychology of Persuasion, New York: William Morrow.

Dell'Orco, M., Marinelli, M. \& Ottomanelli, M., 2014. Simulation of Crowd Dynamics in Panic Situations Using a Fuzzy Logic-Based Behavioural Model. In: Kacprzyk, J (Ed.), Computer-based Modelling and Optimization in Transportation, pp.237-250.

Deutsch, M. \& Gerard, H.B., 1955. A study of normative and informational social influences upon individual judgment. The Journal of Abnormal and Social Psychology, 51(3), pp.629-636.

Fahy, R.F., Proulx, G. \& Aiman, L., 2012. Panic or not in fire : Clarifying the misconception. Fire and Materials, 36, pp.328-338.

Fridolf, K., Nilsson, D. \& Frantzich, H., 2013. Fire Evacuation in Underground Transportation Systems: A Review of Accidents and Empirical Research. Fire Technology, 49(2), pp.451-475.

Guo, R.-Y. \& Huang, H.-J., 2010. Logit-based exit choice model of evacuation in rooms with internal obstacles and multiple exits. Chinese Physics B, 19(3), p.030501.

Guo, R.-Y. \& Huang, H.-J., 2011. Route choice in pedestrian evacuation: formulated using a potential field. Journal of Statistical Mechanics: Theory and Experiment, 2011(04), p.P04018.

Guo, R.-Y., Huang, H.-J. \& Wong, S.C., 2013. A potential field approach to the modeling of route choice in pedestrian evacuation. Journal of Statistical Mechanics: Theory and Experiment, 
2013(02), p.P02010.

Guo, R.-Y., Huang, H.-J. \& Wong, S.C., 2012. Route choice in pedestrian evacuation under conditions of good and zero visibility: Experimental and simulation results. Transportation Research Part B: Methodological, 46(6), pp.669-686.

Gwynne, S.M. et al., 1999. A review of the methodologies used in evacuation modelling. Fire and Materials, 23(6), pp.383-388.

Helbing, D. et al., 2002. Simulation of pedestrian crowds in normal and evacuation situations. Schreckenberg et al. (Eds), Pedestrian and Evacuation Dynamics (2002), pp.21 - 58.

Helbing, D., Farkas, I. \& Vicsek, T., 2000. Simulating dynamical features of escape panic. Nature, 407(6803), pp.487-90.

Helbing, D. \& Johansson, A., 2011. Pedestrian, Crowd and Evacuation Dynamics. In: Meyers, R.A. (Ed.), Extreme Environmental Events, pp.697-716.

Helbing, D. \& Mukerji, P., 2012. Crowd disasters as systemic failures: analysis of the Love Parade disaster. EPJ Data Science, 1(1), p.7. Available at: http://www.epjdatascience.com/content/1/1/7 [Accessed October 18, 2015].

Heliövaara, S. et al., 2012. Pedestrian behavior and exit selection in evacuation of a corridor - An experimental study. Safety Science, 50(2), pp.221-227.

Hensher, D.A., Rose, J.M. \& Greene, W.H., 2005. Applied Choice Analysis: A Primer, Cambridge University Press.

Hoogendoorn, S.P. \& Bovy, P.H.L., 2004. Pedestrian route-choice and activity scheduling theory and models. Transportation Research Part B: Methodological, 38(2), pp.169-190.

Isobe, M., Helbing, D. \& Nagatani, T., 2004. Experiment, theory, and simulation of the evacuation of a room without visibility. Physical Review E, 69(6), p.066132.

Jeon, G.Y. et al., 2011. Evacuation performance of individuals in different visibility conditions. Building and Environment, 46(5), pp.1094-1103.

Judge, T.A. \& Cable, D.M., 2004. The Effect of Physical Height on Workplace Success and Income: Preliminary Test of a Theoretical Model. Journal of Applied Psychology, 89(3), pp.428-441.

Kinateder, M., 2012. Social Influence in Emergency Situations-Studies in Virtual Reality. University of Wuerzburg.

Kirchner, A. \& Schadschneider, A., 2002. Simulation of evacuation processes using a bionics-inspired cellular automaton model for pedestrian dynamics. Physica A: Statistical Mechanics and its Applications, 312(1-2), pp.1-19.

Kobes, M. et al., 2010. Way finding during fire evacuation; an analysis of unannounced fire drills in a hotel at night. Building and Environment, 45(3), pp.537-548.

Korhonen, T., 2011. Fds + Evac Evacuation Model : Recent Developments. In In Proceedings, Fire and Evacuation Modeling Technical Conference 2011. Baltimore, Maryland, p. 8.

Kuligowski, E.D., Peacock, R.D. \& Hoskins, B.L., 2010. A Review of Building Evacuation Models, 2nd Edition, Gaithersburg.

Latane, B. \& Darley, J., 1968. Group inhibition of bystander intervention in emergencies. Journal of personality and social psychology, 10(3), pp.215-221.

Lovreglio, R., Borri, D., et al., 2014. A discrete choice model based on random utilities for exit choice in emergency evacuations. Safety Science, 62, pp.418-426.

Lovreglio, R., 2014. Data-Collection Approaches for the Study of the Decision-Making Process in Fire Evacuations. In 1st SCORE@POLIBA Workshop. Bari.

Lovreglio, R. et al., 2015. The need of latent variables for modelling decision-making in evacuation 
simulations. In IX International Workshop on Planning and Evaluation. Bari.

Lovreglio, R., Fonzone, A., et al., 2014. The Role of Herfing Behaviour in Exit Choice during Evacuation. Social and Behavioral Sciences, 160, pp.390-399.

Lovreglio, R., Fonzone, A. \& Dell'Olio, L., 2015. A Mixed Logit Model for Predicting Exit Choice During Building Evacuations. under review for Transportation Research Part $A$.

Lovreglio, R., Ronchi, E. \& Borri, D., 2014. The validation of evacuation simulation models through the analysis of behavioural uncertainty. Reliability Engineering \& System Safety, 131, pp.66174.

Lovreglio, R., Ronchi, E. \& Nilsson, D., 2015a. A Mixed-Ordered Approach to Investigate Correlations Among Different Affordances in Fire Evacuation. In Human Behaviour in Fire Proceedings of the 6th International Symposium.

Lovreglio, R., Ronchi, E. \& Nilsson, D., 2015b. A model of the decision-making process during preevacuation. Fire Safety Tecnology.

Lovreglio, R., Ronchi, E. \& Nilsson, D., 2015c. Calibrating floor field cellular automaton models for pedestrian dynamics by using likelihood function optimization. Physica A: Statistical Mechanics and its Applications.

Nilsson, D., 2009. Exit choice in fire emergencies - Influencing choice of exit with flashing lights. Lund University.

Nilsson, D. \& Johansson, A., 2009. Social influence during the initial phase of a fire evacuationAnalysis of evacuation experiments in a cinema theatre. Fire Safety Journal, 44(1), pp.71-79.

Nishinari, K. \& Sugawara, K., 2006. Modelling of self-driven particles: Foraging ants and pedestrians. Physica A: Statistical Mechanics and its Applications, (February 2008).

Ortuzar, J. de D. \& Willumsen, L.G., 2011. Modelling Transport, 4th Edition, John Wiley \& Sons.

Pan, X. et al., 2007. A multi-agent based framework for the simulation of human and social behaviors during emergency evacuations. Al \& SOCIETY, 22(2), pp.113-132.

Pan, X., 2006. Computational Modeling Of Human And Social Behaviors For Emergency Egress Analysis. Stanford University.

Purser, D.A., 2003. ASET And RSET: Addressing Some Issues In Relation To Occupant Behaviour And Tenability. Fire Safety Science, 7, pp.91-102.

Ronchi, E. et al., 2015. A Virtual Reality experiment on flashing lights at emergency exit portals for road tunnel evacuation. Fire Technology.

Ronchi, E., Colonna, P., et al., 2012. The evaluation of different evacuation models for assessing road tunnel safety analysis. Tunnelling and Underground Space Technology, 30, pp.74-84.

Ronchi, E., Nilsson, D. \& Gwynne, S.M. V., 2012. Modelling the Impact of Emergency Exit Signs in Tunnels. Fire Technology, 48(4), pp.961-988.

Ronchi, E., Reneke, P.A. \& Peacock, R.D., 2013. A Method for the Analysis of Behavioural Uncertainty in Evacuation Modelling. Fire Technology.

Saloma, C. \& Perez, G.J., 2005. Herding in Real Escape Panic. In: Waldau, N., et al (Ed.). Pedestrian and Evacuation Dynamics 2005, pp.471-479.

Schadschneider, A., 2001. Cellular Automaton Approach to Pedestrian Dynamics - Theory. In M. Schreckenberg \& S.D.Sharma, eds. Pedestrian and Evacuation Dynamics. Springer, p. 11.

Schadschneider, A. et al., 2009. Fundamentals of pedestrian and evacuation dynamics. In A. Bazzan \& F. Klügl, eds. Multi-Agent Systems for Traffic and Transportation Engineering. IGI Global, pp. 124-154.

Sime, J.D., 1983. Affiliative behaviour during escape to building exits. Journal of Environmental 
Psychology, 3(1), pp.21-41.

Sime, J.D., 1985. Movement toward the Familiar: Person and Place Affiliation in a Fire Entrapment Setting. Environment and Behavior, 17(6), pp.697-724.

Simon, H., 1986. Rationality in Psychology and Economics. The Journal of Business, 59(4), pp.S209S224.

Toyama, M., Bazzan, A. \& Silva, R. Da, 2006. An agent-based simulation of pedestrian dynamics: from lane formation to auditorium evacuation. Proceedings of the fifth international joint conference on Autonomous agents and multiagent systems, pp.108-110.

Train, K.E., 2009. Discrete Choice Methods with Simulation, Cambridge: Cambridge University Press. 